\title{
Caracterização fenotípica de raças bubalinas nacionais e do tipo Baio(1)
}

\author{
Lisângela Aparecida Pinheiro Cassiano ${ }^{(2)}$, Arthur da Silva Mariante ${ }^{(3)}$, Concepta McManus $^{(2)}$, \\ José Ribamar Felipe Marques ${ }^{(4)}$ e Norton Amador da Costa ${ }^{(4)}$
}

\begin{abstract}
Resumo - O objetivo deste trabalho foi estudar a influência de fatores ambientais e genéticos nas características fenotípicas de búfalo (Bubalus bubalis) das raças Carabao, Jafarabadi, Murrah e Mediterrâneo e do tipo Baio. Os dados foram analisados usando-se o procedimento GLM do SAS (Statistical Analysis System), cujo modelo estatístico incluiu os efeitos fixos de ano e mês de nascimento, ordem de parto e sexo do animal. As médias encontradas para as variáveis foram: peso ao nascer de $32,79 \mathrm{~kg}$ (de 32,22 a $34,71 \mathrm{~kg}$ ), peso da fêmea adulta de $514,31 \mathrm{~kg}$, primeiro intervalo entre partos de 501,30 dias (de 483 a 564 dias), período de serviço de 191,30 dias (de 86 a 191 dias), idade ao primeiro parto de $1.088,03$ dias (de 1.040 a 1.156 dias) e intervalo entre partos de 380,32 dias (de 373 a 392 dias). O grupo genético dos machos teve influência significativa nas características estudadas, exceto no peso da fêmea adulta. O sexo do bezerro influenciou o peso ao nascer e idade ao primeiro parto. A ordem de parto influenciou o peso ao nascer, período de serviço e intervalo entre partos. $\mathrm{O}$ ano e mês de nascimento influenciaram todas as características estudadas. As médias das características produtivas nas populações de bubalinos criadas na Região Amazônica demonstram que a espécie encontra-se adaptada àquelas condições, constituindo-se em uma alternativa para os criadores.
\end{abstract}

Termos para indexação: Bubalus bubalis, idade ao primeiro parto, intervalo entre partos, fatores ambientais.

\section{Phenotypic characterization of national Brazilian buffalo breeds and Baio type}

\begin{abstract}
The objective of this study was to verify the influence of environmental and genetic factors on buffalo (Bubalus bubalis) of the Carabao, Jaffarabadi, Mediterranean, and Murrah breeds and of the Baio type, utilizing the GLM procedure of SAS (Statistical Analysis System). The mean birth weight was $32.79 \mathrm{~kg}$ (from 32.22 to $34.71 \mathrm{~kg}$ ), mature female weight was $514.31 \mathrm{~kg}$, first calving interval was 501.30 days (from 483 to 564 days), service period was 191.30 days (from 86 to 190 days), age at first calving was $1,088.03$ days (from 1,040 to 1,156 days) and calving interval was 380.32 days (from 373 to 392 days). Sire group significantly affected all traits studied, except mature female weight. Calf sex affected both birth weight and age at first calving. Calving order affected birth weight, service period and calving interval while year of calving significantly affected most traits studied. The productive characteristics studied on the buffalo populations raised on the Brazilian Amazon show that this species is well adapted to those harsh conditions and that it can be considered as an alternative for breeders.
\end{abstract}

Index terms: Bubalus bubalis, age at first calving, calving interval, environmental factors.

(1)Aceito para publicação em 26 de agosto de 2003.

(2) Universidade de Brasília, Fac. de Agronomia e Medicina Veterinária, Caixa Postal 4508, CEP 70910-900 Brasília, DF.E-mail: cassiano@unb.br, concepta@unb.br

${ }^{(3)}$ Embrapa-Centro Nacional de Pesquisa de Recursos Genéticos e Biotecnologia, Caixa Postal 2372, CEP 70770-900 Brasília, DF. E-mail: mariante@ cenargen.embrapa.br

${ }^{(4)}$ Embrapa-Centro de Pesquisa Agroflorestal da Amazônia Oriental, Caixa Postal 48, CEP 66095-100 Belém, PA. E-mail: marques@cpatu.embrapa.br

\section{Introdução}

Estima-se que o aumento do rebanho bubalino mundial seja de $10 \%$ ao ano, refletindo o crescente interesse mundial por esta espécie (Vale, 1988, citado por Sampaio Neto et al., 2001). Mattos (1992) relatou que a população bubalina no Brasil contava com aproximadamente 2,5 milhões de animais e que apresentara um crescimento anual de $12 \%$ nos 10 anos por ele estudados. As raças de búfalos introduzidas 
no Brasil foram as seguintes: Jafarabadi, Murrah, Mediterrâneo e Carabao. O tipo Baio, embora não seja considerado uma raça pela Associação Brasileira de Criadores de Bubalinos (ABCB) apresenta características interessantes à pesquisa e está, juntamente com a raça Carabao, em risco de extinção e descaracterização.

Entre as características da espécie, destacam-se rusticidade, prolificidade, adaptabilidade, vida útil de até 15 anos, precocidade, docilidade, elevada taxa de produtividade de carne e leite, trabalho, aliadas a taxas de natalidade superior a $80 \%$ e de mortalidade inferior a 3\% ao ano (Moreira et al., 1994).

Existe uma grande escassez de informações quanto aos índices reprodutivos das raças de búfalos criadas no país. Segundo Hafez (1995), a avançada idade ao primeiro parto, os problemas relacionados à detecção do cio, o longo período seco nas fêmeas, bem como a perda de libido no macho, são os principais obstáculos ao aumento dos índices reprodutivos nos búfalos.

O intervalo entre partos é muito importante tanto para produção de carne quanto para a produção de leite. Do ponto de vista econômico, o ideal é que esse intervalo seja igual a um ano. Em bovinos, Faria \& Corsi (1979) consideram que a prenhez deva ocorrer no máximo 85 dias após o parto, objetivando a obtenção de um intervalo entre partos próximo a 365 dias. Em búfalas, alguns autores também consideram esse índice como um dos mais importantes parâmetros para se medir a eficiência reprodutiva, com uma média mundial da espécie ao redor de 14,5 meses (Sampaio Neto et al., 2001). Marques et al. (1991) relataram que esta característica é bastante influenciada pela duração da lactação, pois alguns produtores, buscando maior produção de leite, evitam o encerramento da lactação, o que ocasiona o aumento do intervalo entre partos e conseqüente diminuição na eficiência reprodutiva.

Em virtude das condições precárias de manejo nos sistemas de criação extensivos de búfalos no Brasil, a duração média do intervalo entre partos é de quinze meses. Um manejo adequado poderá reduzir este intervalo médio para doze meses, que seria o ideal (Marques, 2000). Não foi encontrado qualquer trabalho sobre o primeiro intervalo entre partos de búfalas, nem seu valor ideal ou os fatores que o influenciam.
Outro parâmetro zootécnico para avaliar a produtividade dos rebanhos é a idade à primeira cria. Este índice está intimamente relacionado com a idade à concepção e à primeira cobertura. Segundo Silveira (2001), a puberdade é atingida por ocasião do primeiro estro, seguido de uma fase luteal normal, enquanto a maturidade sexual ocorre quando o animal atinge a fertilidade funcional, fisiológica e comportamental, que em rebanho Nelore foi alcançada aos 41,93 meses, e foi influenciada pelo mês e pelo ano de nascimento. Marques et al. (1985) afirma que o principal fator que afeta a característica é o manejo nutricional do rebanho, havendo uma variação muito grande entre os outros fatores.

O objetivo deste trabalho foi estudar a influência de fatores ambientais e genéticos nas características fenotípicas de raças bubalinas nacionais e no tipo Baio.

\section{Material e Métodos}

Rebanhos de bubalinos da Embrapa-Centro de Pesquisa Agroflorestal da Amazônia Oriental foram avaliados no período de 1977 a 1995 no Campo Experimental do Baixo Amazonas, situado à margem esquerda do Rio Amazonas, Município de Monte Alegre, PA, cujas coordenadas são $2^{\circ} 0^{\prime} 30^{\prime \prime}$ de latitude sul e $54^{\circ} 4^{\prime} 13^{\prime \prime}$ de longitude oeste, com uma altitude de $30 \mathrm{~m}$, e clima caracterizado como Ami, ou seja, tropical chuvoso, com pequeno período seco. A temperatura média anual é de $26,6^{\circ} \mathrm{C}$, variando entre 22,6 e $31,2^{\circ} \mathrm{C}$. A umidade relativa do ar é, em média, $84 \%$, a precipitação pluvial anual é de cerca de $2.100 \mathrm{~mm}$ e a insolação anual total é de 2.091,5 horas. As principais unidades de relevo são as planícies e baixos planaltos amazônicos, e os solos da região pertencem aos grupos Glei Húmico Orgânico e Meio Orgânico.

Foram utilizados rebanhos de búfalos das raças Jafarabadi (245 registros), Murrah (427 registros), Mediterrâneo (1975 registros), Carabao (237 registros) e do tipo Baio (132 registros), além de mestiços $1 \frac{1}{2}$ Murrah (16 registros), $1 / 2$ Mediterrâneo (53 registros), $1 / 2$ Carabao (152 registros) e $1 / 2$ Baio (185 registros), perfazendo um total de 3.015 animais.

Os animais foram criados extensivamente, em um sistema de conservação em pastagens nativas de terra inundável, dividido em vários retiros, em cuja composição botânica predominam gramíneas forrageiras dos gêneros Paspalum, Luziola, Echinoclhoa, Leersia, Hymenachne, Oriza, Panicum e Brachiaria. O sistema de acasalamento 
foi o de monta natural em campo e práticas de sanidade com respeito às vacinações, combate aos ectoparasitas e endoparasitas, entre outras, foram observadas.

Para determinar os efeitos significativos sobre as características, os dados foram analisados usando procedimento GLM do SAS Institute (1999), cujo modelo estatístico incluiu os efeitos fixos de ano e mês de nascimento, ordem do parto e sexo do animal.

As características analisadas nas fêmeas adultas foram: peso da fêmea adulta (PFA), primeiro intervalo entre partos (IEP 1$)$, idade ao primeiro parto (IPP), período de serviço (PS), e intervalo entre partos (IEP); quanto aos bezerros, foi analisado apenas o peso ao nascer (PN).

\section{Resultados e Discussão}

A média na espécie bubalina de peso ao nascer (PN) foi de 32,79, calculada com base em 2.300 animais (Tabela 1). Dos efeitos fixos analisados, o sexo do bezerro afetou o PN (Tabela 2). Contudo, Schammass et al. (1996), analisando o desenvolvimento ponderal de bubalinos da raça Mediterrâneo, obtiveram médias bem elevadas e PN iguais a $38,7 \mathrm{~kg}$ nos machos e $38,2 \mathrm{~kg}$ nas fêmeas. Com base nesses dados, os autores desconsideraram a influência do sexo no PN.

Tabela 1. Médias, desvios-padrões (DP) e coeficientes de variações das características produtivas e reprodutivas de búfalas.

\begin{tabular}{lcrrr}
\hline Característica & $\mathrm{N}^{\text {(1) }}$ de observacões & \multicolumn{1}{c}{ Média } & \multicolumn{1}{c}{ DP } & C V $(\%)$ \\
\hline PFA (kg) & 81 & 514,47 & 77,70 & 15,32 \\
PN (kg) & 2.300 & 32,79 & 3,27 & 9,26 \\
IEP1 (dias) & 2.098 & 501,30 & 218,61 & 41,97 \\
PS (dias) & 2.098 & 191,30 & 218,61 & 109,99 \\
IPP (dias) & 335 & $1.088,03$ & 75,61 & 7,63 \\
IEP (dias) & 1.181 & 380,32 & 31,09 & 8,31 \\
\hline
\end{tabular}

(1)PFA: peso da fêmea adulta; $\mathrm{PN}$ : peso ao nascer; $\mathrm{IEP}_{1}: 1$ $\mathrm{o}$ intervalo entre partos; PS: período de serviço; IPP: idade ao primeiro parto; IEP: intervalo entre partos.
O PN sofreu influência altamente significativa do mês de nascimento (Tabela 2). Os maiores PN foram observados de janeiro a maio (Tabela 3 ), visto que as búfalas tiveram no seu terço final de gestação maior disponibilidade de comida. Isso reflete a influência ambiental nesta característica. A ordem de parição foi significativa para o PN (Tabela 2). As búfalas atingiram seu ponto ótimo da quinta à sétima parição, pois neste período produziram bezerros maiores, além de melhores índices de PS e IEP (Tabela 4).

A média do peso da fêmea adulta (PFA) foi de $514,47 \mathrm{~kg}$ (Tabela 1). Esta característica não foi afetada por nenhum dos fatores investigados, o que pode ser atríbuido ao pequeno número de observações analisadas, apenas 81 dados entre os cinco grupo genéticos estudados (Tabela 2).

A média da idade ao primeiro parto (IPP) foi de 1.088,03 dias (Tabela 1), ou seja, quase um ano a menos que a média nacional para o rebanho Nelore, que é de 1.304,4 dias (Silveira, 2001).

Na Tabela 2, se observa o efeito significativo do ano do parto na IPP. No entanto, este efeito não pode ser atribuído à seleção do rebanho para esta característica, visto que a mesma variou aleatoriamente durante os anos, não obedecendo a uma ordem crescente ou decrescente (Tabela 5). Acredita-se que a influência de ano esteja relacionada, principalmente, ao manejo, nutrição, clima e sanidade dentro de um ano especifico, ou de determinados períodos de anos estudados. Observações semelhantes foram relatadas por Marques et al. (1985), para esta mesma característica em animais das raças Murrah e Mediterrâneo, bem como em mestiços dessas raças, em que encontrou média de 1.194,6 dias. O autor atribuiu a influência do ano às técnicas de manejo, e às variações de ordem climática.

Tabela 2. Resumo das análises de variâncias (quadrado médio e níveis de significância) para características produtivas e reprodutivas em búfalos ${ }^{(1)}$.

\begin{tabular}{lcccccc}
\hline Característica & PN $(\mathrm{kg})$ & PFA $(\mathrm{kg})$ & PS (dias) & IPP (dias) & IEP1(dias) & IEP (dias) \\
\hline Grupo genético da fêmea & $16,32^{*}$ & $820,44^{\mathrm{ns}}$ & $1.570,99^{\mathrm{ns}}$ & $379,22^{\mathrm{ns}}$ & $726.830,00^{* * *}$ & $43.680,88^{\mathrm{ns}}$ \\
Grupo genético do macho & $51,16^{* *}$ & $4.059,99^{\mathrm{ns}}$ & $20.590,97^{* *}$ & $2.080,58^{*}$ & $10.913,72^{* *}$ & $50.438,85^{\mathrm{ns}}$ \\
Mês do parto & $19,15^{* *}$ & - & $88.097,05^{* *}$ & - & $10.868,12^{* *}$ & $266.938,06^{* *}$ \\
Ano do parto & $101,36^{* *}$ & $7.668,12^{\mathrm{n}}$ & $31.846,42^{* *}$ & $9.863,70^{* *}$ & $1.870,26^{* *}$ & $25.514,41^{* *}$ \\
Sexo do bezerro & $152,22^{* *}$ & - & - & $1.791,26^{* *}$ & - & - \\
Ordem de parição & $13,25^{*}$ & $5.032 .55^{\mathrm{n}}$ & $24.773,69^{* *}$ & - & - & $246.730,83^{* *}$ \\
\hline
\end{tabular}

(1)PN: peso ao nascer; PFA: peso da fêmea adulta; PS: período de serviço; IPP: idade ao primeiro parto; IEP 1 : 1 o intervalo entre partos; IEP: intervalo

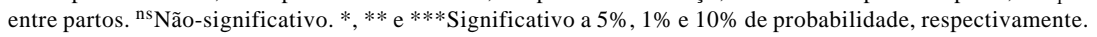


Baruselli (1997) desenvolveu diversos trabalhos referentes à IPP de novilhas da raça Murrah criadas em campo e com bom manejo nutricional, por um período de cinco anos e encontrou uma média de 1.068,9 dias, valor bem semelhante à média encontrada neste trabalho. Não foram observadas diferenças regionais influenciando a IPP no país.

$\mathrm{O}$ intervalo entre partos (IEP) observado foi de aproximadamente 13 meses (Tabela 1). Este resultado foi melhor do que o encontrado por Sampaio Neto et al. (2001), em trabalhos realizados com búfalos da raça Murrah no estado do Ceará, onde se verificou um IEP de 15 meses. Taneja (1999) relatou que as búfalas criadas na Índia apresentaram um IEP médio entre 15 e 16,7 meses.

Zicarelli et al. (1997) afirmam que os búfalos, quando criados em localidades distantes da região equatorial, têm um comportamento reprodutivo influenciado positivamente pela diminuição de horas de luz do dia. No caso deste estudo, realizado na Região Norte brasileira, e em local bem próximo à linha do Equador, estes efeitos foram, provavelmente, causa-

Tabela 3. Efeito de mês dos partos nas características de produção e reprodução de búfalos ${ }^{(1)}$.

\begin{tabular}{lccccc}
\hline Mês do parto & PN (kg) & PS (dias) & IEP1 (dias) & IEP (dias) & IPP (dias) \\
\hline Janeiro & 33,03 & 191 & 602 & 396 & 1.156 \\
Fevereiro & 34,46 & 176 & 555 & 380 & 1.098 \\
Março & 33,40 & 161 & 561 & 385 & 1.168 \\
Abril & 32,91 & 181 & 677 & 399 & 1.103 \\
Maio & 33,41 & 136 & 642 & 377 & 1.022 \\
Junho & 32,74 & 119 & 516 & 393 & 1.024 \\
Julho & 32,64 & 105 & 491 & 396 & 1.029 \\
Agosto & 32,78 & 90 & 467 & 380 & 1.065 \\
Setembro & 32,63 & 94 & 471 & 379 & 1.099 \\
Outubro & 32,75 & 107 & 495 & 373 & 1.082 \\
Novembro & 32,40 & 101 & 498 & 369 & 1.122 \\
Dezembro & 32,52 & 131 & 520 & 366 & 1.138 \\
\hline
\end{tabular}

(1)PN: peso ao nascer; PS: período de serviço; IEP $_{1}$ : 1 o intervalo entr partos; IEP: intervalo entre partos; IPP: idade ao primeiro parto.

Tabela 4. Efeito da ordem dos partos nas características de produção e reprodução de búfalos ${ }^{(1)}$.

\begin{tabular}{lccc}
\hline Qrdem do parto & $\mathrm{PN}(\mathrm{kg})$ & $\mathrm{PS}(\mathrm{dias})$ & $\mathrm{IEP}$ (dias) \\
\hline 1 & 32,40 & 142 & 589 \\
2 & 32,84 & 116 & 513 \\
3 & 32,86 & 104 & 478 \\
4 & 32,93 & 103 & 472 \\
5 & 33,45 & 100 & 472 \\
6 & 32,89 & 99 & 464 \\
7 & 33,31 & 92 & 441 \\
8 & 33,01 & 94 & 466 \\
9 & 33,17 & 102 & 502 \\
$10+$ & 3179 & 105 & 442 \\
\hline
\end{tabular}

(1)PN: peso ao nascer; PS: período de serviço; IEP: intervalo entre partos. dos pelas diferenças estacionais (estações seca e chuvosa bem definidas) que levam a alterações no suprimento de comida e conforto, já que a variação na quantidade de horas de luz por dia, durante todo o ano é muito pequena.

A média do primeiro intervalo entre partos $\left(\operatorname{IEP}_{1}\right)$ foi de 501,30 dias em um PS de 191,30 dias, provavelmente porque as búfalas primíparas ainda estavam em fase de crescimento corporal.

$\mathrm{O}$ ano do parto foi altamente significativo em todas as características estudadas (Tabelas 2 e 5). A ordem de parição foi altamente significativa para PS e IEP (Tabela 2). As búfalas atingem seu ponto ótimo da quinta à sétima parição, pois, neste período além de produzirem bezerros maiores, apresentam um menor PS e um IEP mais curto (Tabela 4).

Quando se analisa a influência do grupo genético nesta característica, observa-se que tanto as búfalas prenhes de touros Carabao quanto as prenhes de touros meio-sangue Carabao mostraram IEP curtos, o que indica a influência da raça Carabao no aumento da fertilidade do rebanho (Tabela 6). Experimentos específicos têm que ser levados em consideração para confirmação desta observação. Nos trabalhos realizados por Baruselli et al. (1993), com a finalidade de avaliar o IEP de um rebanho bubalino já estabilizado, a média do IEP foi de $375,6 \pm 35,4$ dias, valores bem semelhantes aos encontrados em todas as raças analisadas neste trabalho (Tabela 6).

Tabela 5. Efeito do ano dos partos nas características de produção e reprodução de búfalos ${ }^{(1)}$.

\begin{tabular}{lcccc}
\hline Ano do parto & PS (dias) & IEP1 (dias) & IEP (dias) & IPP (dias) \\
\hline 1977 & - & 470 & 372 & 1.093 \\
1978 & 118 & 1.012 & 413 & 1.081 \\
1979 & 81 & 525 & 367 & 1.073 \\
1980 & 77 & 587 & 385 & 1.077 \\
1981 & 119 & 440 & 371 & 1.037 \\
1982 & 96 & 510 & 377 & 1.153 \\
1983 & 108 & 502 & 365 & 1.084 \\
1984 & 92 & 444 & 373 & 1.107 \\
1985 & 110 & 513 & 381 & 1.051 \\
1986 & 85 & 472 & 373 & 998 \\
1987 & 144 & 536 & 377 & 1.109 \\
1988 & 135 & 537 & 375 & 1.093 \\
1989 & 97 & 590 & 384 & 1.061 \\
1990 & 117 & 505 & 389 & 1.143 \\
1991 & 109 & 481 & 379 & 1.106 \\
1992 & 134 & 499 & 384 & 1.061 \\
1993 & 101 & 484 & 378 & 1.075 \\
1994 & - & 509 & 384 & 1.218 \\
1995 & - & 412 & 384 & - \\
\hline
\end{tabular}

(1)PS: período de serviço; $\mathrm{IEP}_{1}: 1$ o intervalo entre partos; IEP: intervalo entre partos; IPP: idade ao primeiro parto. 
Vários fatores interferem na duração do período de serviço (PS), e entre eles podem ser citados o fator nutricional (búfalas com carências alimentares apresentam período mais prolongado), a idade da búfala (novilhas tendem a apresentar maiores períodos), fatores ambientais e genéticos (Tabela 2). O PS foi afetado significativamente por todos os fatores, com exceção do grupo genético das fêmeas.

O efeito touro também foi importante na redução do PS. Zicarelli et al. (1997) recomendam, inclusive, que em rebanhos bubalinos se mantenha constantemente a presença de um reprodutor no período pósparto. Essas condições são essenciais e indispensáveis para um rápido reinício da atividade ovariana pós-parto, que, juntamente com a involução uterina, interferem no PS. Outro fator que afeta o PS é a amamentação contínua, por inibir o reinício da atividade ovariana, aumentando o PS.
Em búfalas que pariram nos primeiros meses do ano, o PS foi mais alto, pois após a involução do útero, as planícies estão alagadas, reduzindo a quantidade e a qualidade dos pastos oferecidos às búfalas (Tabela 3). Os bubalinos são considerados de dupla aptidão, ou seja, para a produção de carne e leite e, portanto, devem ser levados em consideração os resultados das Tabelas 2 e 3, para a época de parição. No geral, a concentração de partos otimiza a mãode-obra, uma vez que facilita o manejo. Entretanto, para uma recomendação mais exata, seriam necessárias informações referentes à taxa de mortalidade mensal e o peso à desmama dos animais.

A distribuição dos partos ao longo dos meses apresentou maior concentração entre agosto e outubro (Figura 1). Tal fato indica os meses de dezembro a fevereiro como período ideal ao estabelecimento de uma estação de monta. Entretanto, para criações

Tabela 6. Efeitos dos grupos genéticos de fêmeas e machos nas características produtivas e reprodutivas de bufalos ${ }^{(1)}$.

\begin{tabular}{|c|c|c|c|c|c|c|}
\hline Raca & $\mathrm{N}^{0}$ de_observaç̃es & $\mathrm{PN}(\mathrm{kg})$ & PS (dias) & $\mathrm{IEP}_{1}$ (dias) & $\operatorname{IEP}$ (dias) & $\mathrm{IPP}$ (dias) \\
\hline & \multicolumn{6}{|c|}{ Grupo Genético da fêmea } \\
\hline Baio & 85 & 33,42 & 115 & 498 & 377 & 1.054 \\
\hline Carabao & 117 & 33,79 & 135 & 547 & 393 & 1.154 \\
\hline Jafarabadi & 117 & 34,46 & 146 & 584 & 386 & 1.112 \\
\hline Mediterrâneo & 963 & 32,26 & 103 & 479 & 378 & 1.082 \\
\hline Murrah & 204 & 33,33 & 106 & 524 & 376 & 1.058 \\
\hline $1 / 2$ Murrah & 16 & 32,70 & 142 & 567 & 370 & 1.074 \\
\hline 1/2 Mediterrâneo & 53 & 32,48 & 120 & 502 & 382 & 1.075 \\
\hline $1 / 2$ Baio & 80 & 32,93 & 126 & 552 & 384 & 1.121 \\
\hline \multirow[t]{2}{*}{$1 / 2$ Carabao } & 81 & 33.20 & 121 & 522 & 383 & 1.106 \\
\hline & \multicolumn{6}{|c|}{ Grupo Genético do macho } \\
\hline Baio & 47 & 34,71 & 86 & 484 & 373 & 1.122 \\
\hline Carabao & 120 & 32,72 & 129 & 537 & 392 & 1.156 \\
\hline Jafarabadi & 128 & 34,45 & 144 & 564 & 388 & 1.143 \\
\hline Mediterrâneo & 1.011 & 32,22 & 105 & 483 & 378 & 1.089 \\
\hline Murrah & 223 & 33,26 & 102 & 519 & 376 & 1.040 \\
\hline $1 / 2$ Baio & 105 & 33,15 & 130 & 545 & 381 & 1.130 \\
\hline $1 / 2$ Carabao & 71 & 33.70 & 136 & 486 & 385 & 1.042 \\
\hline
\end{tabular}

(1)PN: peso ao nascer; PS: período de serviço; $\mathrm{IEP}_{1}$ : 1 o intervalo entre partos; IEP: intervalo entre partos; IPP: idade ao primeiro parto.

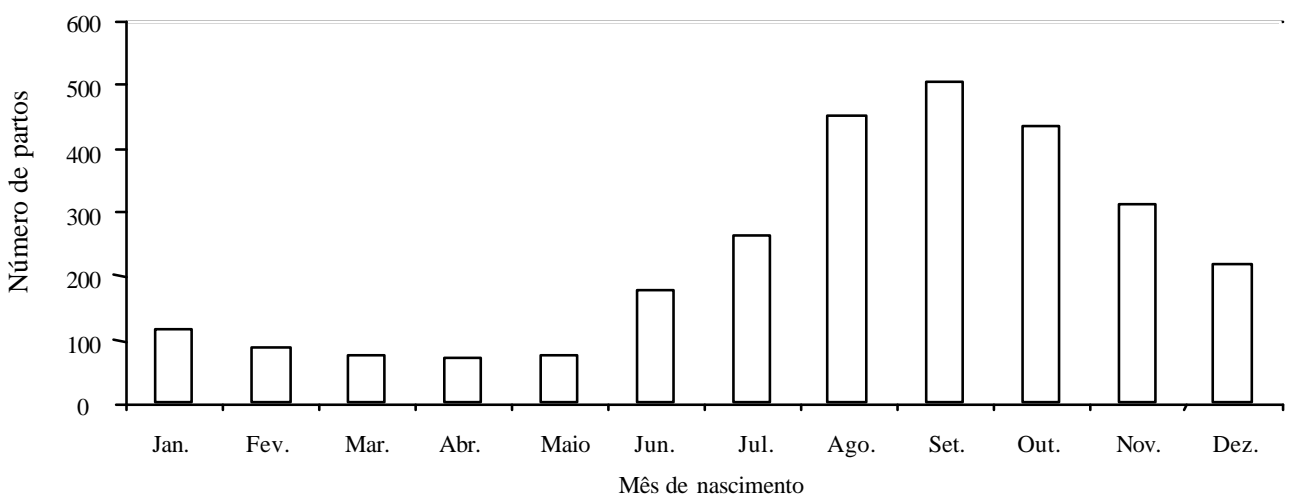

Figura 1. Distribuição dos partos de búfalas ao longo do ano. 
voltadas à produção de leite destinada a laticínios especializados em fabricação de queijos especiais com leite de búfala, a concentração das parições é um fator indesejável. Em um trabalho desenvolvido na Itália, Zicarelli et al. (1997) mostram que é possível distribuir com mais uniformidade os partos durante o ano. Os primeiros passos para a desestacionalização devem ser ensaiados com cautela e em uma pequena parcela do rebanho, para que o criador não tenha uma queda brusca da fertilidade, pois o mês de parição foi altamente significativo em todas as características analisadas (Tabela 2).

Animais da raça Jafarabadi apresentaram o PS mais longo e conseqüentemente maior IEP. Em termos de cruzamento, as fêmeas que eram $1 / 2$ Murrah tiveram o PS mais longo. Búfalas gestantes de touros $1 / 2$ Carabao mostraram um encurtamento do PS (Tabela 6).

\section{Conclusões}

1. Das características analisadas em todos os grupos genéticos, apenas o peso da fêmea adulta não sofre influência dos fatores de meio ambiente, bem como do sexo e do grupo genético dos touros.

2. Há superioridade adaptativa da espécie bubalina à Região Amazônica.

\section{Referências}

BARUSELLI, P. S. Reprodução de bubalinos. In: SIMPÓSIO BRASILEIRO DE BUBALINOCULTURA,

1., 1996, Cruz da Almas. Anais... Cruz das Almas: Universidade Federal da Bahia, 1997. p. 117-153.

BARUSELLI, P. S.; OLIVEIRA, J. F. S.; MENDES, M. L. M.; JORGE, A. M.; FUJII, T.; PALAZZO, J. P. C. Diagnóstico da bubalinocultura do Vale do Ribeira. Campinas: Coordenadoria de Assistência Técnica Integral, 1993. 16 p. (Documento Técnico, 94).

FARIA, V. P.; CORSI, M. Os índices zootécnicos na pecuária leiteira. In: SIMPÓSIO SOBRE PECUÁRIA LEITEIRA, 2., 1979, São José dos Campos. Anais... Campinas: Fundação Cargill, 1979. p. 40-61.

HAFEZ, E. S. E. (Ed.). Reproduction in farm animals. $6^{\text {th }}$ ed. Philadelphia: Lea \& Febiger, 1993. 573 p.

MARQUES, J. R. F. Búfalos: o produtor pergunta, a Embrapa responde. Brasília: Embrapa-SCT/EmbrapaCPATU, 2000. 176 p. (Coleção 500 Perguntas).
MARQUES, J. R. F.; BARBOSA, N.; CARVALHO, L. O. D. M.; OTAVIO, L.; LOURENÇO JÚNIOR, J. B.; COSTA, N. A.; BATISTA, E. A. M.; RIBEIRO, M. J. P. S. S.; BARBOSA, C.; RAMOS, A. A. Características da produção leiteira de búfalos Bubalus bubalis L.). Belém: Embrapa-CPATU, 1991.36 p. (Boletim de Pesquisa, 121).

MARQUES, J. R. F.; BATISTA, H. A. M.; NASCIMENTO, C. N. B.; LOURENÇO JÚNIOR, J. B.; CARVALHO, L. O. D. M.; COSTA, N. A.; ANDRADE, V. J.; PIMENTEL, E. S. Idade à primeira cria em bubalinos no trópico úmido brasileiro. Belém: EmbrapaCPATU, 1985. 13 p. (Boletim de Pesquisa, 70).

MATTOS, J. C. A. Patrimônio genético do rebanho bubalino brasileiro. São Paulo: Associação Brasileira de Criadores de Búfalo, 1992. 29 p.

MOREIRA, P.; COSTA, A. L.; VALENTIN, J. F. Comportamento produtivo e reprodutivo de bubalinos mestiços Murrah-Mediterrâneo em pastagem cultivada em terra firme, no Estado do Acre. Rio Branco: EmbrapaCPAF-Acre, 1994. 19 p. (Boletim de Pesquisa, 13).

SAMPAIO NETO, J. C.; MARTINS FILHO, R.; LÔBO, R. N. B.; TONHATI, H. Avaliação dos desempenhos produtivos e reprodutivos de um rebanho bubalino no Estado do Ceará. Revista Brasileira de Zootecnia, Viçosa, MG, v. 30, n. 2, p. 368-373, 2001.

SAS INSTITUTE (Cary, Estados Unidos). Statistical analysis system: user's guide. Cary, 1999. 595 p.

SCHAMMASS, E. D.; KAWATOKO, M.; BARBOSA, C.; CAMARGO, D. F. V.; MATTOS, J. C. A.; MACEDO, M. P. Desenvolvimento ponderal de bubalinos da raça mediterrânea. In: REUNIÃO ANUAL DA SOCIEDADE BRASILEIRA DE ZOOTECNIA, 33., 1996, Fortaleza. Anais... Viçosa, MG: Universidade Federal de Viçosa, 1996. v. 1, p. 301-303.

SILVEIRA, J. C. Estudo da influência de fatores genéticos e ambientais sobre as características produtivas e reprodutivas em bovinos Nelore no Estado de Mato Grosso do Sul. 2001. 67 f. Dissertação (Mestrado em Ciências Agrárias) - Universidade de Brasília, Brasília, 2001.

TANEJA, V. K. Dairy breeds and selection. In: FALVEY, L.; CHANTALAKHANA, C. (Ed.). Smallholder dairying in the tropics. Nairobi: International Livestock Research Institute, 1999. $462 \mathrm{p}$.

ZICARELLI, L. de F. C.; FRANCILLO, M.; PACELLI, C.; VILLA, E. E. Influence of insemination technique and ovulation time on fertility percentage in synchronized buffaloes. In: WORLD BUFFALO CONGRESS, 5., 1997, Caserta. Proceedings... Caserta: [s.n.], 1997. p. 732-737. 